\title{
Sol-Gel Silica-on-Silicon Buried-Channel EDWAs
}

\author{
W. Huang and R. R. A. Syms, Senior Member, IEEE
}

\begin{abstract}
Silica-on-silicon erbium-doped waveguide amplifiers (EDWAs) fabricated by the sol-gel route are demonstrated. The preparation of stable sols is first described, with emphasis on identifying chemical routes that allow the incorporation of sufficient concentration of erbium without precipitation or gelation. Erbium-doped glasses containing various codopants, such as phosphorus, aluminum, germanium and ytterbium are formed and used in the construction of buried channel guide EDWAs. A range of optical measurements is presented, and the effects of the dopants in eliminating erbium ion quenching and improving pumping efficiency are evaluated. The best material system-Er/Yb codoped aluminophosphosilicate glass-has low background loss and a net gain of $1.1 \mathrm{~dB} / \mathrm{cm}$.
\end{abstract}

Index Terms-Erbium-doped waveguide amplifiers (EDWAs), erbium, optical amplifier, sol-gel, waveguides.

\section{INTRODUCTION}

G REAT PROGRESS has been made in developing erbium-doped fiber amplifiers (EDFAs) for operation at a 1535-nm wavelength [1], [2]. For Metro applications, there is a strong incentive to reduce the size and cost of EDFAs through miniaturization and improved packaging. One possibility is to use erbium-doped waveguide amplifiers (EDWAs), which can be constructed in arrays and also combined with pump lasers and filters. The use of a silicon substrate also simplifies fiber connection, making a silica-on-silicon EDWA a desirable goal.

Because of their short length, EDWAs require heavy $\mathrm{Er}^{3+}$ doping without concentration-dependent effects [3], [4]. In the past, this has been difficult to achieve using silicate glass hosts, especially in a silica-on-silicon format. In this paper, we describe the development of operating silica-on-silicon EDWAs by a sol-gel process that may have the potential to overcome these difficulties. We begin by summarizing the state of the art.

\section{A. Existing EDWAs}

Previously, EDWAs have been formed by ion exchange in silicate [5]-[8] or phosphate glass [9]-[18] and by implantation of $\mathrm{Er}^{3+}$ into a variety of materials, including $\mathrm{SiO}_{2}$ [19], [20], $\mathrm{SiON}$ [21], and $\mathrm{Al}_{2} \mathrm{O}_{3}$ [22], [23]. Buried channel guides have been formed in Er-doped silicate glasses deposited by electron beam evaporation [24] and sputtering [25]-[30] and also in sputtered phosphate glass [31]. Er-doped lasers and amplifiers have been formed by solution or aerosol doping of flame hydrolysis deposited (FHD) silica-on-silicon [32]-[39] and by using erbium

Manuscript received June 18, 2002; revised February 20, 2003. This work was supported by the Engineering and Physical Sciences Research Council (EPSRC) under Grant GR/N17157.

The authors are with the Optical and Semiconductor Devices Section, Department of Electrical and Electronic Engineering, Imperial College, London SW7 2BT, U.K. (e-mail: r.syms@ic.ac.uk).

Digital Object Identifier 10.1109/JLT.2003.812417 chelate as an erbium source during plasma-enhanced chemical vapor deposition (PECVD) [40]-[43]. Er-doped alumina has also been deposited by PECVD [44].

The performance of EDWAs has been compared in [4]. The available gain is strongly material-dependent; internal gains of $4.1 \mathrm{~dB} / \mathrm{cm}$ [31] and over $1.8 \mathrm{~dB} / \mathrm{cm}$ [14] have been achieved in ion-exchanged phosphate glass, $1.1 \mathrm{~dB} / \mathrm{cm}$ in soda-lime silicate glass [25]-[30], $0.6 \mathrm{~dB} / \mathrm{cm}$ in implanted $\mathrm{Al}_{2} \mathrm{O}_{3}$ [22], and $0.35 \mathrm{~dB} / \mathrm{cm}$ in PECVD silica [43]. In many systems, amplifying splitters have also been developed [8], [16], [17], [43].

\section{B. Silica-on-Silicon EDWAs}

In silica-on-silicon, thick glass layers are used to isolate the guided mode from the substrate. FHD and PECVD are generally used to deposit these layers because of their high rates. Low propagation loss can be obtained in high-density silica-on-silicon circuits using $\mathrm{GeO}_{2}$ as an index-raising dopant and $\mathrm{P}_{2} \mathrm{O}_{5}$ and $\mathrm{B}_{2} \mathrm{O}_{3}$ to lower the melt temperature [45], [46].

Unfortunately, $\mathrm{Er}^{3+}$ clustering in silica is widely recognized as leading to ion-ion effects, such as cooperative upconversion [3], [4], reducing the lifetime of the metastable ${ }^{4} \mathrm{I}_{13 / 2}$ level and the achievable gain. The dispersion of $\mathrm{Er}_{2} \mathrm{O}_{3}$ may be improved by codoping with $\mathrm{P}_{2} \mathrm{O}_{5}, \mathrm{Al}_{2} \mathrm{O}_{3}$, and $\mathrm{Ga}_{2} \mathrm{O}_{3}$ [38], [39]. However, high internal gain has so far only been achieved in a silica-on-silicon EDWA using low $\mathrm{Er}^{3+}$ concentration and a long path in a phosphosilicate glass (PSG) [33], [34] or Al-doped germanosilicate glass [42], [43]. Furthermore, the weak absorption of $\mathrm{Er}^{3+}$ at $980 \mathrm{~nm}$ requires the use of high-power pumps. Pump power may be reduced using additional codopants, such as $\mathrm{Yb}_{2} \mathrm{O}_{3}$ [3], [7], [12]-[18]. $\mathrm{Yb}$ has a large absorption cross section at $980 \mathrm{~nm}$ and may transfer energy nonradiatively to the ${ }^{4} \mathrm{I}_{11 / 2}$ level of $\mathrm{Er}^{3+}$.

Although erbium may be incorporated in silicate glasses by both FHD and PECVD, there are difficulties associated with the high process temperatures in the former case, and the low vapor pressure of most erbium compounds in the latter [4], [40]. There is therefore a need to investigate other processes for depositing Er-doped silicate glass, which can incorporate the full range of codopants needed to tailor the $\mathrm{Er}^{3+}$ environment.

\section{Sol-Gel Silica-on-Silicon}

One possibility is the sol-gel method, which allows very flexible chemistry and low process temperatures. Work in this area was originally performed on thin planar guides in $\mathrm{TiO}_{2}-\mathrm{SiO}_{2}$ [47]-[50]. Buried channel guides have been formed by densification using an infrared (IR) laser [51]-[54] and by ultraviolet (UV) exposure of silica hybridized with a photopolymerizable organic [55], [56]. Photoinscribed ridge guides have also been made by solvent-assisted lithography [57]. The use of ormocers allows thick layers to be formed at low temperatures without 
cracking but introduces vibrational absorption bands in the near IR window [58].

Thick layers of silicate glasses can be formed as multilayers by repetitive use of spin-coating and rapid thermal annealing (SC-RTA), with careful control of the annealing temperature [47]. These layers may then be formed into buried channel guides by reactive ion etching and burial [60], [61]. An alternative strip-loaded geometry with higher coupling and propagation loss has also been developed [62]. Both these systems were based on $\mathrm{TiO}_{2}-\mathrm{SiO}_{2}$. However, $\mathrm{TiO}_{2}$ is relatively unsuitable, because of its high process temperatures [60] and tendency to form crystalline rutile or anatase phases [63].

Since then, improved buried guides have been developed in phosphosilicate [64], borophosphosilicate [65], [66], and germanophosphosilicate glass [67]. The buried channel geometry allows low fiber coupling loss. The use of $\mathrm{P}_{2} \mathrm{O}_{3}$ and $\mathrm{B}_{2} \mathrm{O}_{3}$ allow SC-RTA temperatures to be lowered and scattering loss to be reduced by reflow. $\mathrm{P}_{2} \mathrm{O}_{5}$ reduces $\mathrm{O}-\mathrm{H}$ absorption loss (an advantage shared by $\mathrm{Al}_{2} \mathrm{O}_{3}$ [62]), and replacement of $\mathrm{TiO}_{2}$ by $\mathrm{GeO}_{2}$ as an index-raising dopant allows low bending loss without crystallization. The best performance for passive sol-gel guides to date has been obtained in $\mathrm{GeO}_{2}-\mathrm{P}_{2} \mathrm{O}_{3}-\mathrm{SiO}_{2}$ [67].

\section{Sol-Gel EDWAs}

Methods for incorporating $\mathrm{Nd}, \mathrm{Er}$, and $\mathrm{Yb}$ into sol-gel monoliths were developed some time ago [68]-[70], and considerable effort has now been expended on rare-earth-doped sol-gel waveguide amplifiers [71]. Initial investigations were performed on $\mathrm{Nd}$-doped glasses [72], [73], but attention is now concentrated on Er doping, using hosts ranging from pure $\mathrm{SiO}_{2}$ [74] to $\mathrm{TiO}_{2}-\mathrm{SiO}_{2}$ [75]-[78], $\mathrm{Al}_{2} \mathrm{O}_{3}-\mathrm{SiO}_{2}$ [79], [80], $\mathrm{P}_{2} \mathrm{O}_{5}-\mathrm{SiO}_{2}$ [81], $\mathrm{Al}_{2} \mathrm{O}_{3}-\mathrm{TiO}_{2}-\mathrm{SiO}_{2}$ [82], and $\mathrm{GeO}_{2}-\mathrm{SiO}_{2}$, with both weak [83] and high [84] germania contents.

Improvements in lifetime arising from aluminum [73] and phosphorus [78] codoping have been identified, as has the improvement in pump efficiency arising from codoping with ytterbium [82] and, more recently, yttrium [85]. However, crystallization has been observed with $\mathrm{Al}_{2} \mathrm{O}_{3}$ at high annealing temperatures [79]. Low process temperatures have also been shown to be important to preserve luminescence lifetime [86].

Because of an overwhelming concentration on materials characterization or planar guide structures, almost all data on sol-gel amplifiers has been gathered without the demonstration of working EDWAs, especially in a silica-on-silicon format. Until 2002, the best results were achieved (by our group) using strip loaded guides [77]. However, high fiber coupling and propagation losses prevented any net gain being achieved, the quoted gain $(1.1 \mathrm{~dB} / \mathrm{cm})$ being relative. Recently, the first sol-gel silica-on-silicon EDWA with net fiber-device-fiber gain was demonstrated (again, by us), based on a buried channel guide in Er/Yb : AlPSG [87]. This achievement is a significant advance for sol-gel processing.

\section{E. Summary}

In this paper, we present a more systematic comparison of different EDWAs fabricated in $\mathrm{GeO}_{2}-\mathrm{P}_{2} \mathrm{O}_{3}-\mathrm{SiO}_{2}$ and $\mathrm{Al}_{2} \mathrm{O}_{3}-\mathrm{P}_{2} \mathrm{O}_{5}-\mathrm{SiO}_{2}$ hosts by the sol-gel method and demonstrate the advantage of Er/Yb:AlPSG compositions. In
Section II, the chemical processes needed to obtain usable rare-earth-doped sols with different compositions are presented. In Section III, waveguide fabrication (including film deposition, thermal treatment, and reactive ion etching) is described. In Section IV, optical measurements (including spontaneous emission spectra, gain spectra, gain variations, noise figure, and metastable lifetimes) are given for several different sol-gel EDWAs, concentrating on devices with realistic operating characteristics. The conclusion is presented in Section V.

\section{SOL PREPARATION}

In this section, we describe the sol preparation processes used to form a variety of glasses evaluated in completed EDWAs. All are strongly multicomponent. They include: Er:GePSG, Er : AlSG, Er : AlPSG, Er/Yb : PSG, Er/Yb : AlPSG.

\section{A. Rare-Earth Precursors}

The precursors for erbium and ytterbium were based on alcohol solutions. A wide range of erbium-bearing compounds is potentially available. However, erbium oxide, hydroxide, phosphate, and carbonate are insoluble in alcohol, and erbium chloride is only weakly soluble. Erbium nitrate is highly soluble, and we experienced no difficulty in forming a heavily doped $(0.5 \mathrm{M})$ solution. Alkoxides such as $\operatorname{Er}\left(\mathrm{OC}_{3} \mathrm{H}_{7}\right)_{3}$ [erbium isopropoxide, or $\left.\mathrm{Er}(\mathrm{OPr})_{3}\right]$ and $\operatorname{Er}\left(\mathrm{O}_{2} \mathrm{C}_{5} \mathrm{H}_{7}\right)_{3}$ (erbium acetoacetate) are also only weakly soluble in alcohol. Erbium alkoxides are hydrolyzed very easily, so handling must be carried out under dry $\mathrm{N}_{2}$, and any alcohol must be anhydrous. Unfortunately, it is hard to prevent hydrolysis by the residual water present in a sol, which causes precipitation of $\operatorname{Er}(\mathrm{OH})_{3}$.

Because of the ionic bonding property of erbium ions, there is little difference in the structure of the resulting material when erbium nitrate is used as a precursor instead of erbium isopropoxide. Erbium nitrate solutions were therefore often used as erbium precursors, and ytterbium nitrate solutions as ytterbium precursors.

\section{B. GePSG Host System}

The overall sol preparation routes were based on recipes for passive glasses. We begin with EDWAs based on a GePSG host material. Fig. 1 shows the acid catalyzed process eventually developed, which is based on the use of $\mathrm{Si}(\mathrm{OEt})_{4}$ or TEOS as a precursor for $\mathrm{SiO}_{2}$, an alcohol solution of $\mathrm{P}_{2} \mathrm{O}_{5}$, and $\mathrm{Ge}(\mathrm{OEt})_{4}$ or TEOG as a precursor for $\mathrm{GeO}_{2}$. This recipe is merely a modification of that developed for GePSG [67], but there are difficulties involved in the apparently simple step of adding an $\mathrm{Er}_{2} \mathrm{O}_{3}$ precursor to a multicomponent sol, and many permutations were investigated before a successful process was evolved.

First, we found that solutions of $\mathrm{ErCl}_{3}$ in propan-2-ol or ethanol caused immediate precipitation of a white compound (presumably $\mathrm{ErPO}_{4}$ ) when they are added to a PSG sol at point A in Fig. 1, through reaction with phosphorus alkoxides. Second, we found that solutions of erbium isopropoxide and acetoacetate could be added without immediate precipitation, but only up to a certain limit. The limit increases approximately linearly with $\mathrm{P}_{2} \mathrm{O}_{5}$ content, as shown in Fig. 2, and corresponds to $\sim 0.1 \mathrm{~mol} \% \mathrm{Er}_{2} \mathrm{O}_{3}$ per mol\% $\mathrm{P}_{2} \mathrm{O}_{5}$, a ratio of 


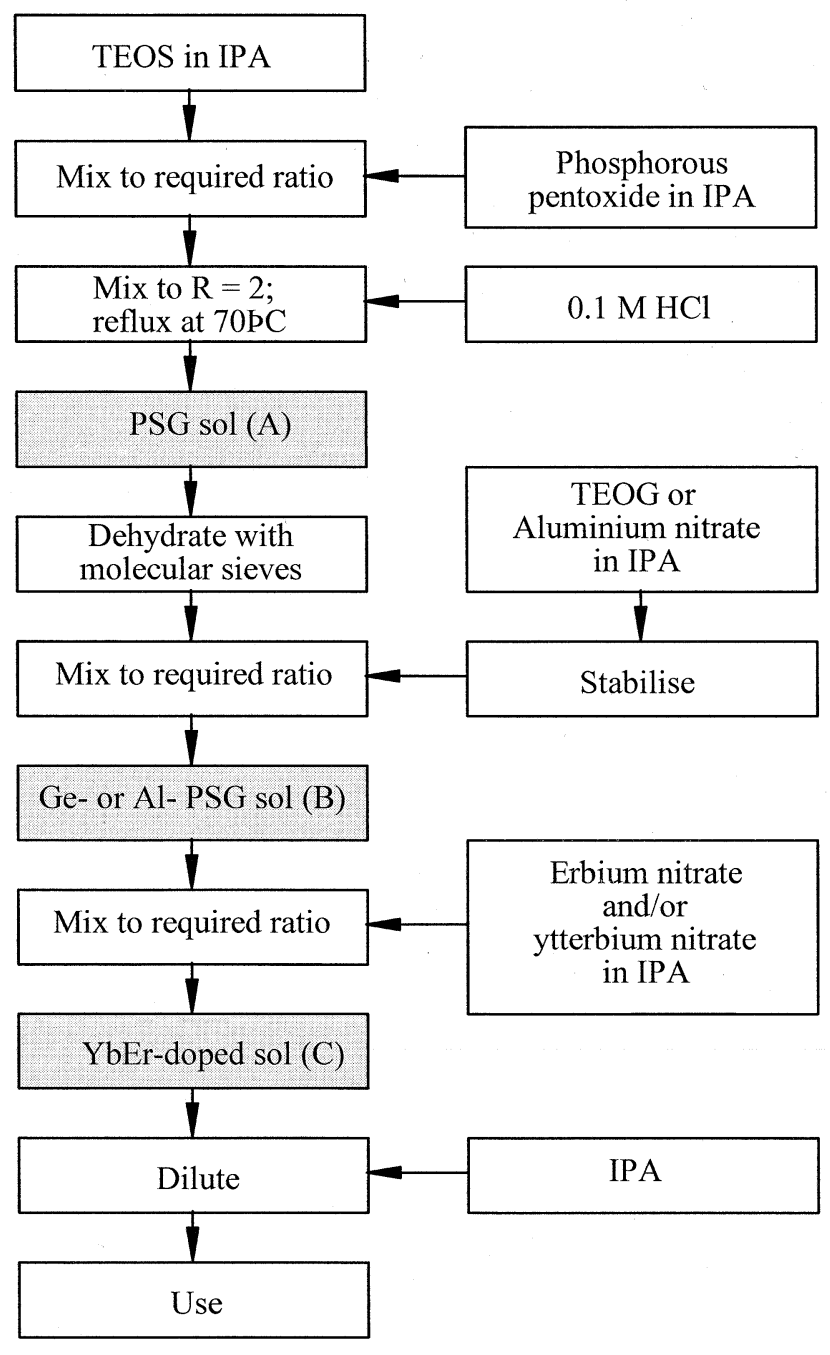

Fig. 1. Process flowchart for preparation of erbium-doped silicate glass sols.

$1: 10$. However, gradual precipitation still occurs. As a result, it is preferable to add the erbium precursor only after the phosphorus alkoxides are fully reacted.

The erbium precursor is therefore added after incorporating the germanium precursor, at point B in Fig. 1. However, the previous step has its own difficulties, because of the rapid hydrolysis of TEOG. Previously, we developed a dehydration process for PSG sols using sodium aluminum silicate molecular sieves; without this, addition of the TEOG caused immediate gelation [67]. Fig. 3 shows the variation of the gelation time (in a closed container) with sieve concentration, for a GePSG sol containing $5 \mathrm{~mol} \% \mathrm{GeO}_{2}$ and $10 \mathrm{~mol} \% \mathrm{P}_{2} \mathrm{O}_{5}$, which illustrates how the gelation time may be extended by dehydration.

Using $\mathrm{Er}(\mathrm{OPr})_{3}$, we have found that precipitation can be prevented by increasing the acidity of the solution. However, the alkaline sieves used to dehydrate the PSG sol so that TEOG may be incorporated also lower its acidity, so that increasing the amount of sieve lowers the $\mathrm{Er}_{2} \mathrm{O}_{3}$ content that can subsequently be incorporated without precipitation. This relationship is shown superimposed on Fig. 3. We have used an optimum sieve concentration of about $80 \mathrm{mg} / \mathrm{ml}$, which combines a shelf life of several days with a useful $\mathrm{Er}_{2} \mathrm{O}_{3}$ content ( $\left.\sim 0.5 \mathrm{~mol} \%\right)$.

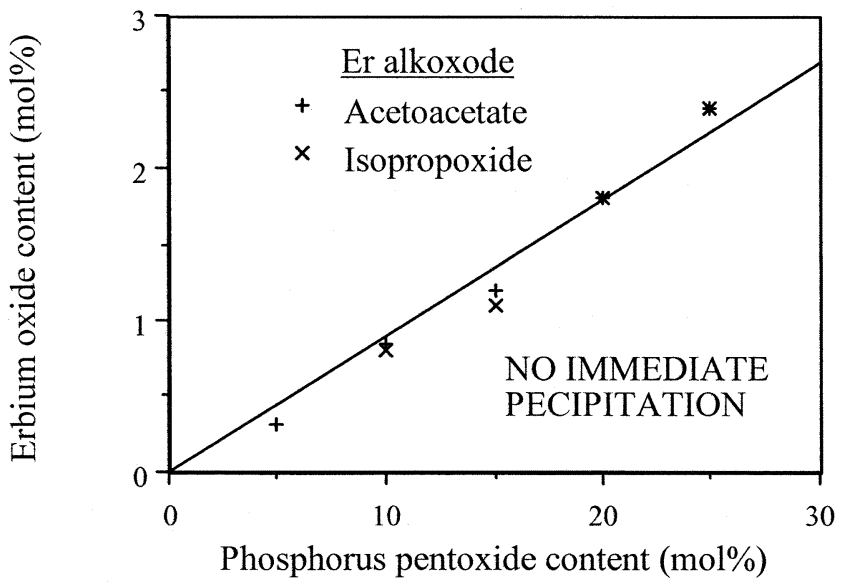

Fig. 2. Variation of the maximum $\mathrm{Er}_{2} \mathrm{O}_{3}$ content (before precipitation occurs in a PSG sol) with $\mathrm{P}_{2} \mathrm{O}_{5}$ content, based on alcohol solutions of $\mathrm{Er}\left(\mathrm{OC}_{3} \mathrm{H}_{7}\right)_{3}$ and $\operatorname{Er}\left(\mathrm{O}_{2} \mathrm{C}_{5} \mathrm{H}_{7}\right)_{3}$.

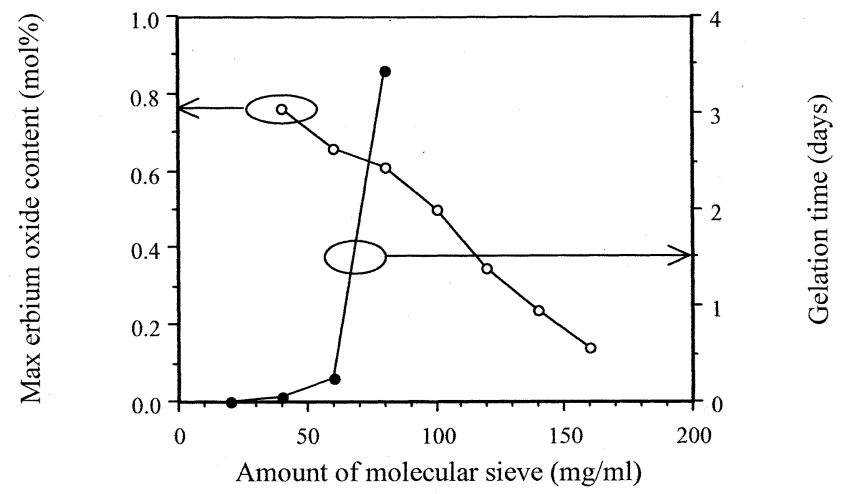

Fig. 3. Variation of gelation time and maximum $\mathrm{Er}_{2} \mathrm{O}_{3}$ doping level with concentration of molecular sieve for a GePSG sol containing $10 \mathrm{~mol} \% \mathrm{P}_{2} \mathrm{O}_{5}$ and $5 \mathrm{~mol} \% \mathrm{GeO}_{2}$.

Similar concentrations were achieved using erbium nitrate solutions.

$\mathrm{Er}(\mathrm{OPr})_{3}$ itself affects the gelation time. For example, Fig. 4 shows the variation of gelation time in an open container with $\mathrm{Er}_{2} \mathrm{O}_{3}$ content, for Er: GePSG sols containing $5 \mathrm{~mol} \% \mathrm{GeO}_{2}$ and $10 \mathrm{~mol} \% \mathrm{P}_{2} \mathrm{O}_{5}$. Gelation occurs more rapidly as the Er content rises. However, for heavily doped sols times of 10-20 h could routinely be achieved.

Similar experiments were carried out with ytterbium. We found that $\mathrm{Yb}$ has very similar properties to $\mathrm{Er}$ in the sense of achieving a stable sol, and therefore found that the total rare-earth content (i.e., the combined amount of $\mathrm{Yb}_{2} \mathrm{O}_{3}$ and $\mathrm{Er}_{2} \mathrm{O}_{3}$ ) is also limited to $\sim 0.5 \mathrm{~mol} \%$. This result has important implications for EDWAs, since it implies that co-doping with $\mathrm{Yb}$ reduces the maximum Er concentration. An improvement in pump efficiency can therefore only be achieved at the expense of a reduction in overall gain.

\section{AlPSG and AlSG Host Systems}

We now describe the alternative AlPSG and AlSG hosts. Since $\mathrm{Al}_{2} \mathrm{O}_{3}$ has a similar effect to $\mathrm{GeO}_{2}$ on refractive index but is well known to improve rare-earth ion performance in silica, the replacement of $\mathrm{GeO}_{2}$ by $\mathrm{Al}_{2} \mathrm{O}_{3}$ may be advantageous. In 


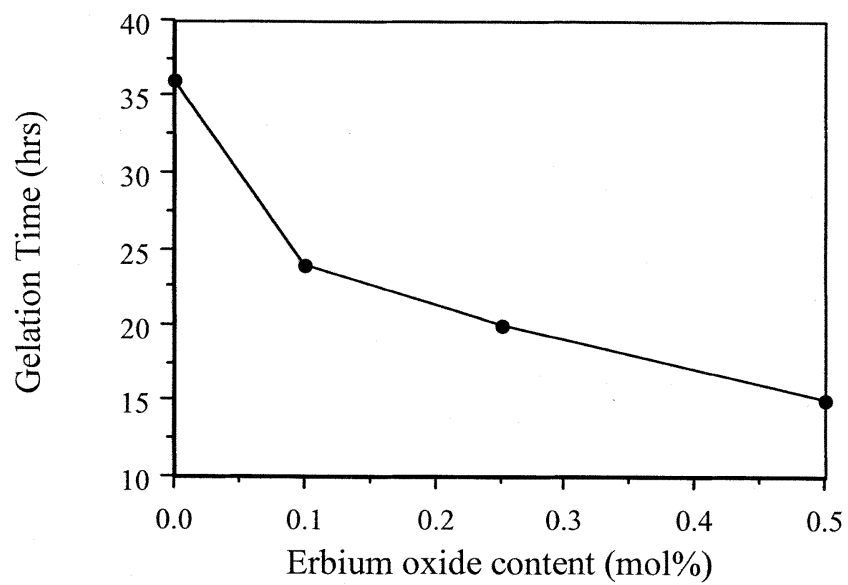

Fig. 4. Variation of gelation time with $\mathrm{Er}_{2} \mathrm{O}_{3}$ doping level, for $\mathrm{Er}$ : GePSG sols containing $10 \mathrm{~mol} \% \mathrm{P}_{2} \mathrm{O}_{5}$ and $5 \mathrm{~mol}^{2} \mathrm{GeO}_{2}$.

our experience, erbium-doped aluminophosphosilicate sols have the same precipitation problem as Er:GePSG sols, and the addition of $\mathrm{Al}$ precursors also accelerates precipitation.

After several trials, sols that were sufficiently stable for spin coating were obtained by using a similar acidity adjustment method to the one in Fig. 1, but with aluminum nitrate as the $\mathrm{Al}_{2} \mathrm{O}_{3}$ precursor. However, the other available $\mathrm{Al}$ alkoxides (e.g., aluminum isopropoxide and aluminum 2-4-butoxide) all failed to produce a sol that could be spin-coated. AlSG sols were produced by a similar process, except for the omission of the $\mathrm{P}_{2} \mathrm{O}_{5}$ solution.

\section{EDWA FABRICATION}

In this section, we describe the methods used to fabricate complete buried-channel-guide EDWAs in silica-on-silicon, using the sol-gel precursors previously discussed.

\section{A. Layer Deposition}

Using the procedure in Fig. 1, clear and stable sols of Er:GePSG, Er: AlSG, Er: AlPSG, and Yb-codoped Er: PSG and $\mathrm{Er}$ : AlPSG containing targeted rare-earth concentrations up to $0.5 \mathrm{~mol} \%$ were prepared. Dehydration was performed in $48 \mathrm{~h}$ using $80 \mathrm{mg}$ of molecular sieve per milliliter of solution. Thick films were built up on 4-in Si wafers by SC-RTA. Sols were dispensed from a syringe with a $0.1-\mu \mathrm{m}$ pore filter, spin-coated at $2000 \mathrm{rpm}$ and annealed in an AG Associates Heatpulse rapid thermal annealer.

Both the gel and glass films generally had good optical properties. However, the quality deteriorated with increasing rare-earth concentration. For example, Fig. 5 shows lightand dark-field microscope views of two Er:GePSG films, each containing $5 \mathrm{~mol} \% \mathrm{GeO}_{2}$ and $10 \mathrm{~mol} \% \mathrm{P}_{2} \mathrm{O}_{5}$ and doped with $0.25 \mathrm{~mol} \%$ and $0.5 \mathrm{~mol} \% \mathrm{Er}_{2} \mathrm{O}_{3}$, respectively. Each film contains particulate inclusions larger than the filter pore. However, the heavily doped layer clearly contains more large inclusions, which have caused some cracking. The most likely explanation is that the erbium phosphate reaction is not completely suppressed and produces precipitates during spin coating itself. Rare-earth concentrations were therefore

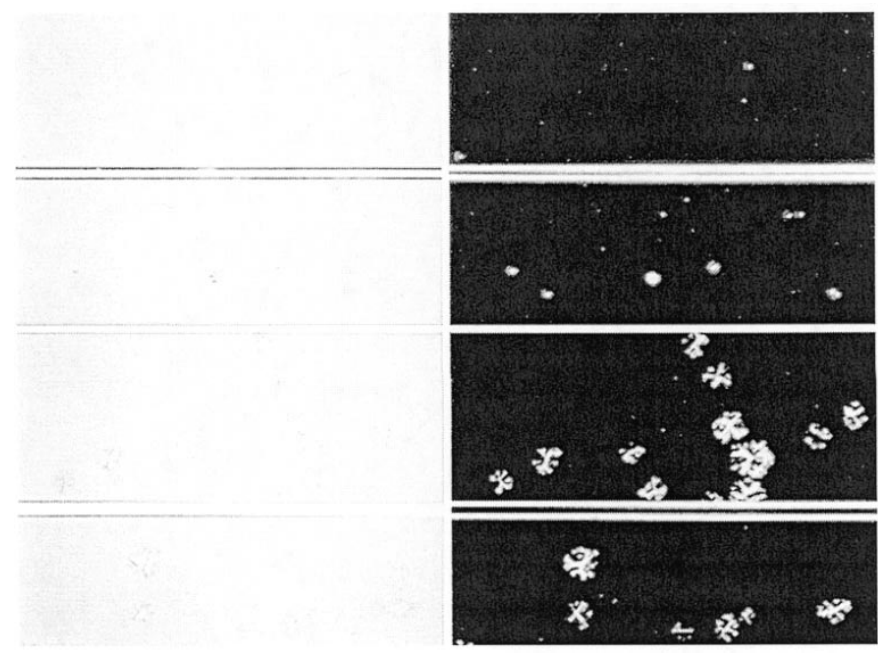

Fig. 5. Light field (left-hand side) and dark field (right-hand side) views of Er: PSG films containing $10 \mathrm{~mol} \% \mathrm{P}_{2} \mathrm{O}_{5}$ and $5 \mathrm{~mol} \% \mathrm{GeO}_{2}$, and $0.25 \mathrm{~mol} \%$ $\mathrm{Er}_{2} \mathrm{O}_{3}$ (upper) and $0.5 \mathrm{~mol} \% \mathrm{Er}_{2} \mathrm{O}_{3}$ (lower).
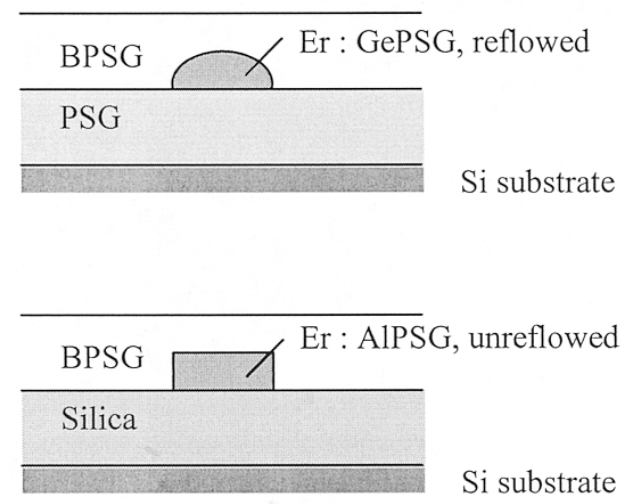

(a)

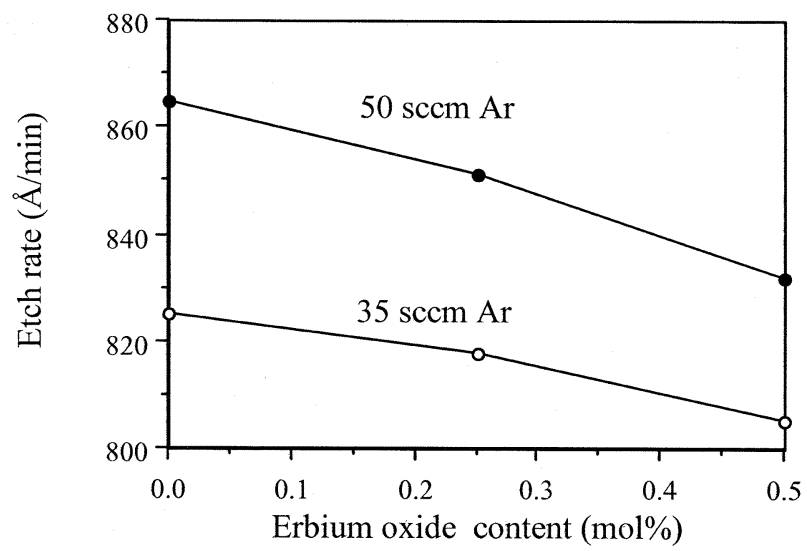

(b)

Fig. 6. (a) Cross section of active guides based on Er: GePSG and Er: AlPSG. (b) Variation of reactive ion etch rate with composition for Er: GePSG.

restricted to $0.5 \mathrm{~mol} \%$, a level consistent with earlier sol preparation experiments.

\section{B. Device Fabrication}

Complete EDWAs were constructed using two different approaches, as shown in Fig. 6(a). In each case, different glasses 


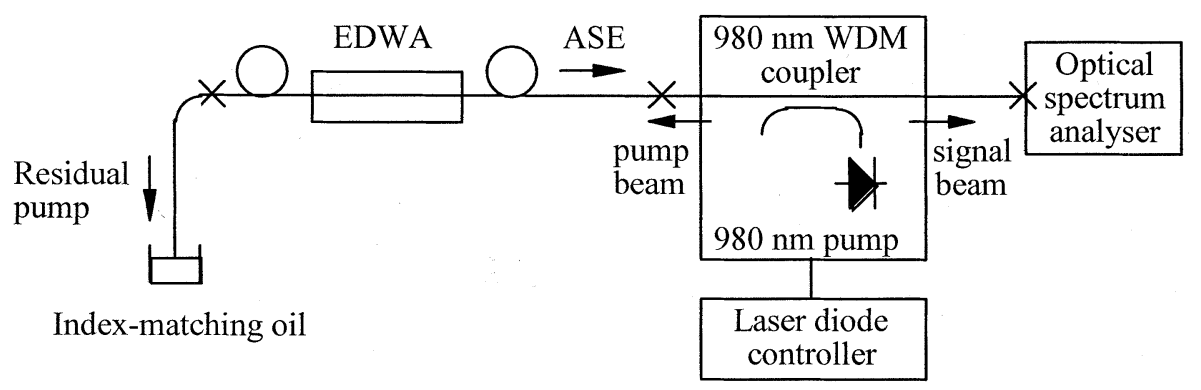

(a)

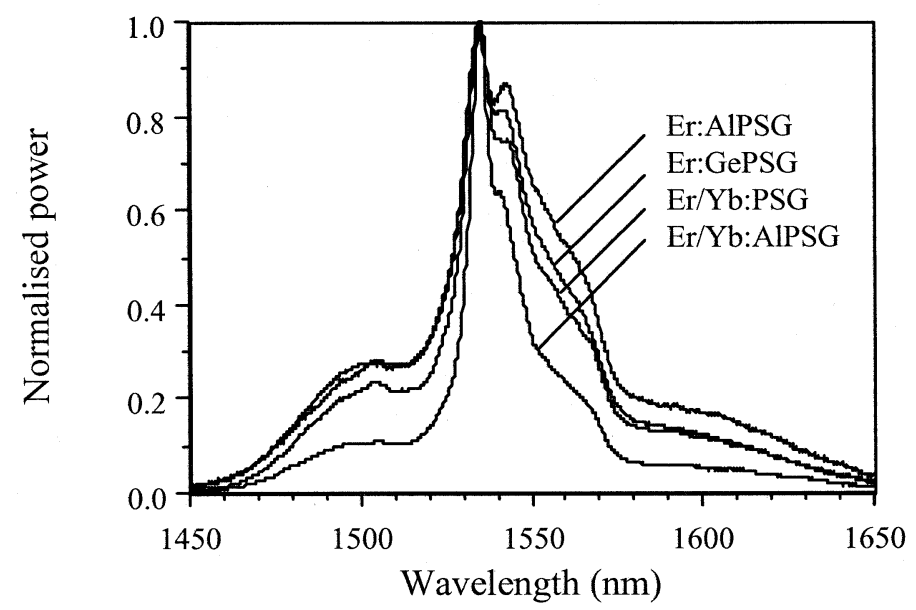

(b)

Fig. 7. (a) Arrangement for measurement of spontaneous emission. (b) Emission spectra for 1) Er: GePSG, 2) Er/Yb : PSG, 3) Er : AlPSG, and 4) Er/Yb : AlPSG sol-gel EDWAs.

are used in different regions of the guide structure, which consists of an etched core deposited on a thick buffer layer and buried by a thick cladding. The cores were formed by reactive ion etching, with a $\mathrm{Cr}$ hard mask. Some samples were etched at Nortel Networks, Harlow, U.K.

For Er: GePSG EDWAs, the glasses in all three layers were formed by the sol-gel process. For the buffer, the PSG was used to lower the RTA process temperature [64]. For the core, erbium-doped germanophosphosilicate glass (Er: GePSG) was used. This glass contained more $\mathrm{P}_{2} \mathrm{O}_{5}$ than the buffer to allow a pinned base reflow [66], and $\mathrm{GeO}_{2}$ to control the refractive index [67]. Finally, for the cladding, borophosphosilicate glass (BPSG) was used to allow reflow of the cladding without distorting the core [66].

For Er: AlSG, Er : AlPSG, Er/Yb : PSG, and Er/Yb : AlPSG, sol-gel glass was only used for the core, which was not reflowed. The buffer was 13- $\mu$ m-thick thermal oxide, and the cladding was a thick layer of BPSG formed by PECVD. Both materials were deposited at Nortel Networks, Harlow.

In all cases, cores were deposited by SC-RTA. The individual layer thickness was $2000 \AA$, and each layer was typically annealed at $850{ }^{\circ} \mathrm{C}$ for $10 \mathrm{~s}$ in $\mathrm{O}_{2}$. However, higher temperatures were required for glasses lacking $\mathrm{P}_{2} \mathrm{O}_{5}$ [66]. Before core etching, the glasses were consolidated at $1000{ }^{\circ} \mathrm{C}$ for $1 \mathrm{~h}$. All GePSG, AlPSG, and AlPSG hosts contained $10 \mathrm{~mol} \% \mathrm{P}_{2} \mathrm{O}_{5}$. AlSG and AlPSG hosts contained 5 and $2.5 \mathrm{~mol} \% \mathrm{Al}_{2} \mathrm{O}_{3}$, respectively.
Because erbium tends to act as an etch stop, care is required to obtain cores of suitably high quality by reactive ion etching. For example, Fig. 6(b) shows the variation of etch rate with $\mathrm{Er}_{2} \mathrm{O}_{3}$ concentration, for Er: GePSG etched in an Oxford Plasma Technology RIE80 parallel plate etcher using a mixture of $\mathrm{CHF}_{3}$, $\mathrm{O}_{2}$ and Ar gas, with flow rates of 50, 1, and 30-50 sccm (standard cubic centimeters per minute), respectively. The etching rate falls gradually as the erbium concentration rises. The rate can be raised by increasing the Ar flux from 30 to $50 \mathrm{sccm}$, which increases sputtering. However, etching should be carried out using high RF power and low pressure to prevent micromasking by involatile erbium by-products. Here, $240-\mathrm{W}$ radio frequency (RF) power, $25-\mathrm{m}$ torr pressure, and $610-\mathrm{V}$ dc bias were used.

\section{Erbium Concentration}

In order to assess the effect of ytterbium on pumping efficiency, sols containing either Er alone or Er and $\mathrm{Yb}$ together were prepared. Two different concentration ratios (containing $\mathrm{Er}: \mathrm{Yb}$ ratios of $1: 1$ and $1: 3$ ) were used. The $\mathrm{Er}_{2} \mathrm{O}_{3}$ and $\mathrm{Yb}_{2} \mathrm{O}_{3}$ concentrations were both $0.25 \mathrm{~mol} \%$ in the former case, and $0.125 \mathrm{~mol}_{2} \mathrm{Er}_{2} \mathrm{O}_{3}$ and $0.375 \mathrm{~mol} \% \mathrm{Yb}_{2} \mathrm{O}_{3}$ in the latter. For an $\mathrm{Er}_{2} \mathrm{O}_{3}$ content of $0.25 \mathrm{~mol} \%$, the erbium doping level corresponds to $1.17 \mathrm{wt} \% \mathrm{Er}^{3+}$ ions. Assuming a density of $2.3 \mathrm{~g} / \mathrm{cm}^{3}$, this level is equivalent to $9.7 \times 10^{25} \mathrm{ions} / \mathrm{m}^{3}$. For an $\mathrm{Er}_{2} \mathrm{O}_{3}$ content of $0.125 \mathrm{~mol} \%$, the doping level is reduced to $4.75 \times 10^{25}$ ions $/ \mathrm{m}^{3}$. 


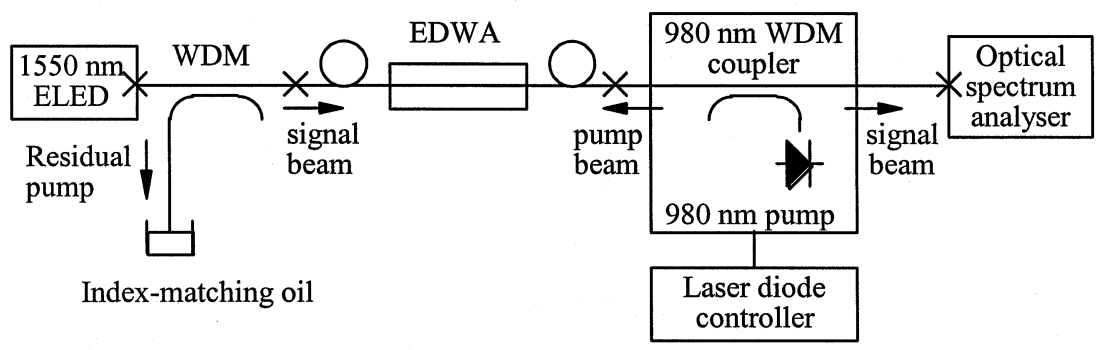

(a)

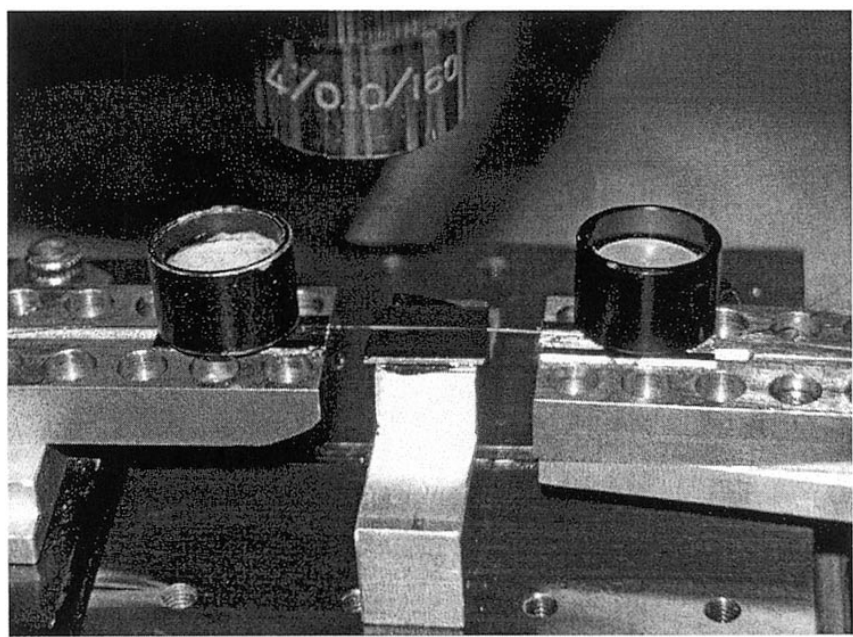

(b)

Fig. 8. (a) Arrangement for measurement of transmission spectra. (b) Device-under-test.

\section{OPTICAL MEASUREMENTS}

In this section, we describe measurements of completed EDWAs. Core widths ranged from 3-6 $\mu \mathrm{m}$, and initial experiments were performed to identify cores that were single mode (SM) at pump and signal and wavelengths. EDWAs were cleaved to length and butt-coupled to SM fiber, using an index-matching gel capable of high-power handling.

\section{A. Spontaneous Emission Measurements}

Spontaneous emission spectra were measured as shown in Fig. 7(a). EDWAs were pumped through a wavelength-divisionmultiplexing (WDM) coupler using a Nortel WS59229 980-nm wavelength laser diode. A residual pump light was dumped into index-matching oil, and backward-traveling spontaneous emission was coupled into an Agilent $86140 \mathrm{~B}$ optical spectrum analyzer (OSA) set to 1-nm resolution. Most sol-gel compositions yielded EDWAs worth detailed evaluation. The exception was Er: AlSG; in this case, the insertion loss was very high. The most likely explanation is crystallization of the active glass, coupled with a weak index difference between the core and the cladding.

The spontaneous emission spectra of EDWAs based on Er:AlPSG, Er:GePSG, Er/Yb:PSG, and Er/Yb:AlPSG are shown in Fig. 7(b), on a linear plot. The spectra of both the Er:AlPSG and Er:GePSG devices are similar to the PECVD Er: PSG device reported by Shuto [40], although the additional use of germanium and aluminum has resulted in a slight broadening. However, the spectra of the $\mathrm{Er} / \mathrm{Yb}$ : PSG and
$\mathrm{Er} / \mathrm{Yb}:$ AlPSG devices are significantly narrower. In particular, the $\mathrm{Er} / \mathrm{Yb}$ : AlPSG device shows a full-width at half-maximum (FWHM) of only $19 \mathrm{~nm}$, which suggests that the glass structure must be strongly altered by the addition of $\mathrm{Yb}$.

\section{B. Gain Measurements}

Broad-band gain measurement was performed as shown in Fig. 8(a). Light from an Agilent 8342A 1550-nm edge-emitting diode (ELED) was coupled into the EDWA from its free end via a second WDM coupler, so that pump and signal were counterpropagating, and then into the OSA. Fig. 8(b) shows a device under test. A green guiding streak is visible due to upconversion from the pump level of $\mathrm{Er}^{3+}\left({ }^{4} \mathrm{I}_{11 / 2}\right)$. In this process, Er ions are excited to the ${ }^{4} \mathrm{~F}_{7 / 2}$ level. From there, they decay nonradiatively to the ${ }^{4} \mathrm{~S}_{3 / 2}$ level. The lifetime of this level is relatively long compared with other levels, except the signal level $\left({ }^{4} \mathrm{I}_{13 / 2}\right)$, and the green light is emitted following a radiative decay to ground $\left({ }^{4} \mathrm{I}_{15 / 2}\right)$.

Transmission spectra were obtained by comparing fiber-fiber and fiber-device-fiber measurements, and these spectra were used to determine gains and losses. Fig. 9(a)-(c) show transmission spectra at different pump powers for 5-cm-long EDWAs in $\mathrm{Er} / \mathrm{Yb}$ : $\mathrm{PSG}, \mathrm{Er}$ : GePSG, and Er: AlPSG, respectively. The data are presented as log-linear plots. In the first and second cases, transparency is not achieved at the highest power available $(175 \mathrm{~mW})$, even though the erbium-induced absorption is relatively low. In the third, transparency is almost achieved, even though the erbium absorption is significantly higher. These results highlight the importance of including $\mathrm{Al}$ as a codopant. 


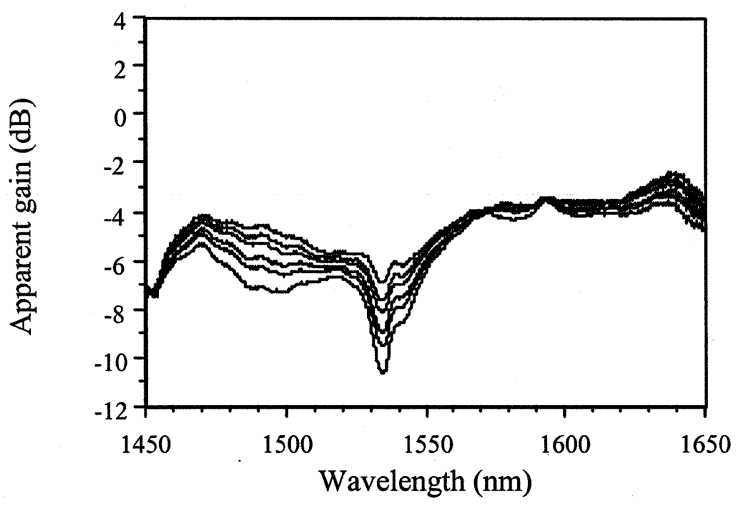

(a)

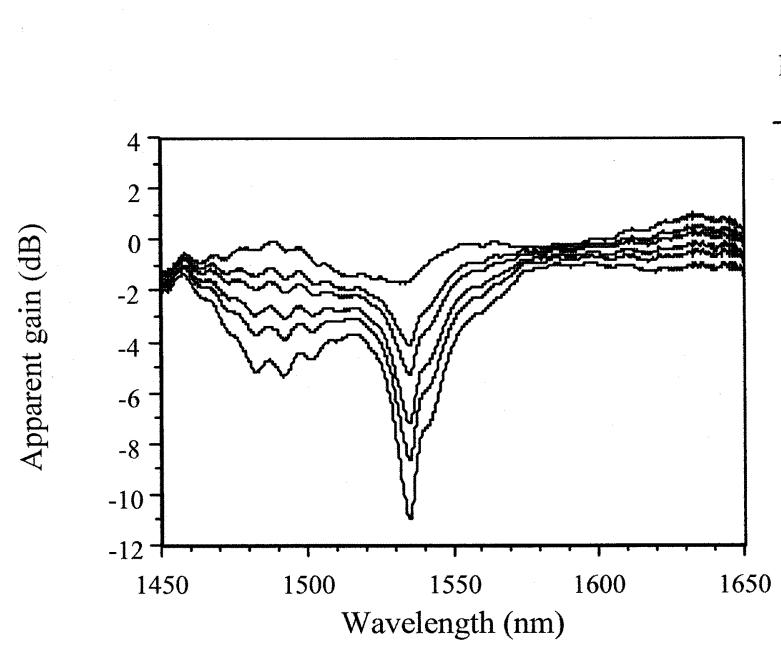

(c)
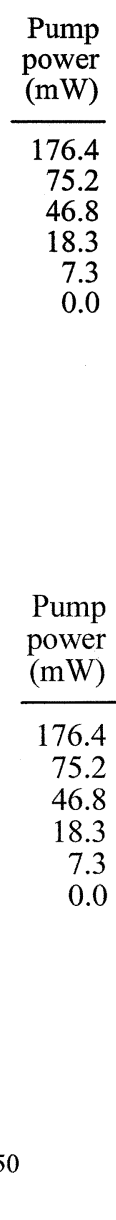

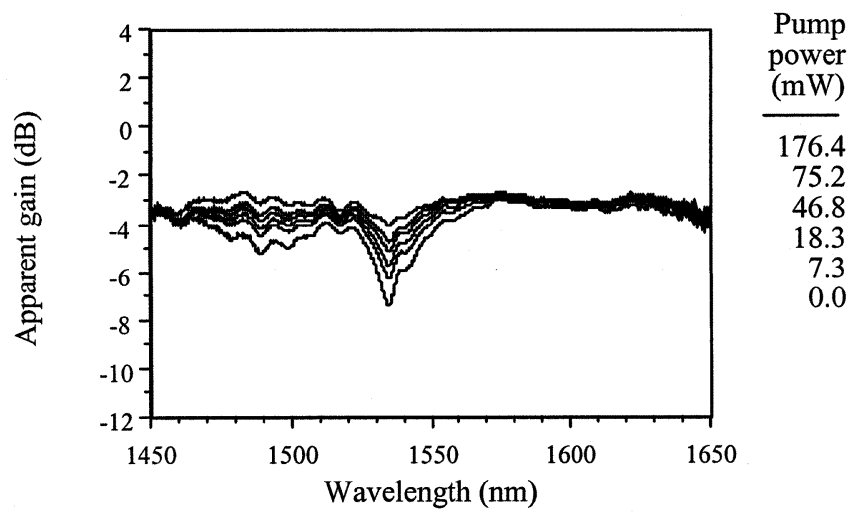

(b)

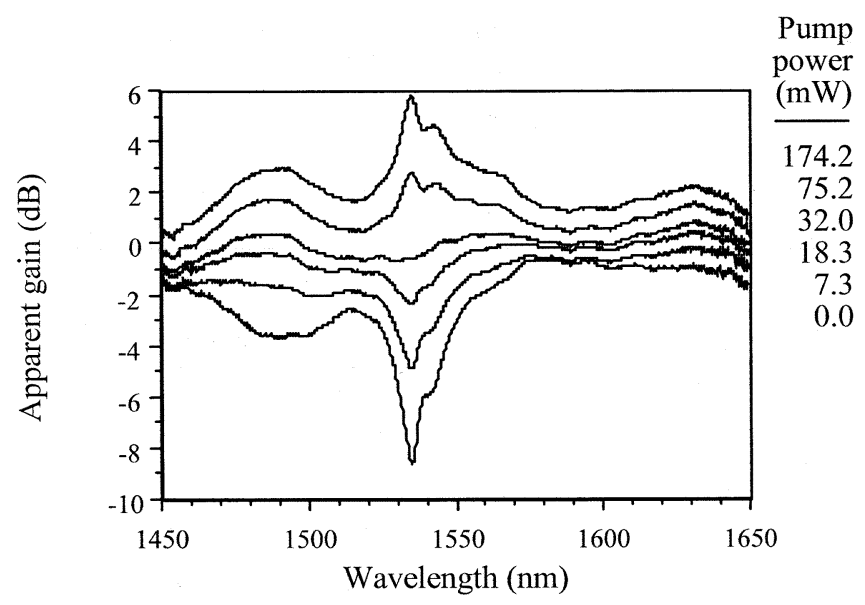

(d)

Fig. 9. Transmission spectra for 5-cm-long 3- $\mu$ m-wide EDWAs in (a) Er/Yb : PSG, (b) Er : GePSG, (c) Er : AlPSG, and (d) Er/Yb : AlPSG [87], at different pump laser powers.

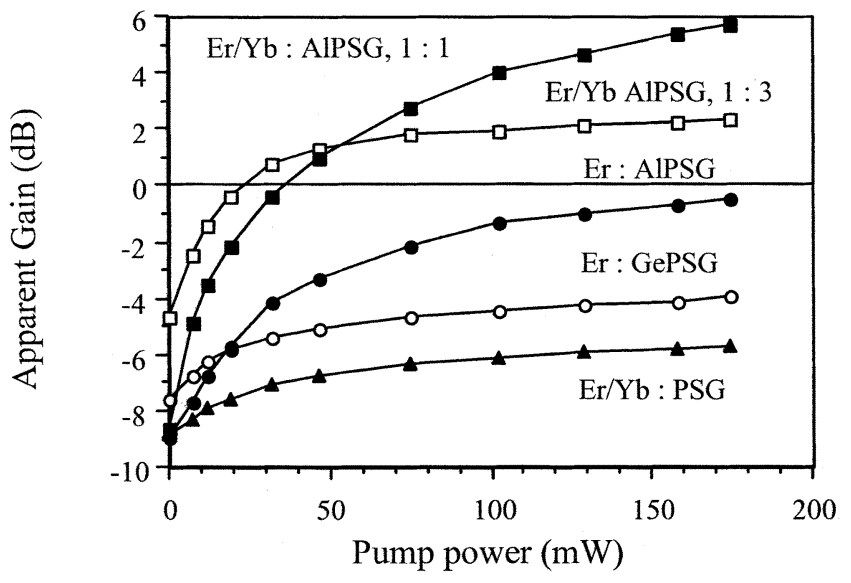

Fig. 10. Variation of gain with pump power for EDWAs formed in 1) $\mathrm{Er} / \mathrm{Yb}: \mathrm{PSG}$, 2) $\mathrm{Er}: \mathrm{GePSG}$, 3) Er: AlPSG, 4) and 5) Er/Yb : AlPSG with $\mathrm{Er} / \mathrm{Yb}$ ratios of $1: 1$ and $1: 3$.

Fig. 9(d) (from [87]) shows similar transmission spectra for an $\mathrm{Er} / \mathrm{Yb}$ : AlPSG EDWA. The $\mathrm{Er}_{2} \mathrm{O}_{3}$ and $\mathrm{Yb}_{2} \mathrm{O}_{3}$ concentrations are both $0.25 \mathrm{~mol} \%$, so that the $\mathrm{Er}: \mathrm{Yb}$ ratio is $1: 1$. In this case, transparency, inversion and net gain are all achieved. Transparency is achieved at a pump power of $27 \mathrm{~mW}$. The net gain for the maximum available power of $175 \mathrm{~mW}$ is around $5.75 \mathrm{~dB}$, corresponding to a net (fiber-device-fiber) gain per $\mathrm{cm}$ of $5.75 / 5=1.1 \mathrm{~dB} / \mathrm{cm}$. These results emphasize the advantage of incorporating both $\mathrm{Al}$ and $\mathrm{Yb}$.

Fig. 10 shows the variation of gain with pump power, for 5-cm-long EDWAs in the different compositions. No EDWA lacking either $\mathrm{Al}$ or $\mathrm{Yb}$ reached transparency at the highest power, even when shortened to $2 \mathrm{~cm}$. However, the performance of the Er: AlPSG EDWA is significantly better than the Er: GePSG sample, which in turn outperforms the $\mathrm{Er} / \mathrm{Yb}$ : $\mathrm{PSG}$ device. Net fiber-device-fiber gain is achieved for the $\mathrm{Er} / \mathrm{Yb}$ : AlPSG EDWA described previously. A net gain of $2.3 \mathrm{~dB}$ is also achieved using for a similar EDWA containing $0.125 \mathrm{~mol} \% \mathrm{Er}_{2} \mathrm{O}_{3}$ and $0.375 \mathrm{~mol} \% \mathrm{Yr}_{2} \mathrm{O}_{3}$, i.e., an $\mathrm{Er}: \mathrm{Yb}$ ratio of 1:3. A lower pump power $(\sim 13 \mathrm{~mW})$ was needed for transparency, and there is a noticeable improvement in pump efficiency. However, reduced Er doping has resulted in a lower gain per $\mathrm{cm}$.

For the EDWA with the Er: Yb ratio of $1: 1$, Fig. 11 shows the variation of fiber-device-fiber loss and gain at 1533.6-nm length at $175-\mathrm{mW}$ pump power. By extrapolating the loss to zero length, the coupling loss may be estimated at $\sim 0.5 / 2=$ $0.25 \mathrm{~dB} /$ facet. The background propagation loss obtained by a measurement at $1310 \mathrm{~nm}$ is around $0.1 \mathrm{~dB} / \mathrm{cm}$. Both figures are 


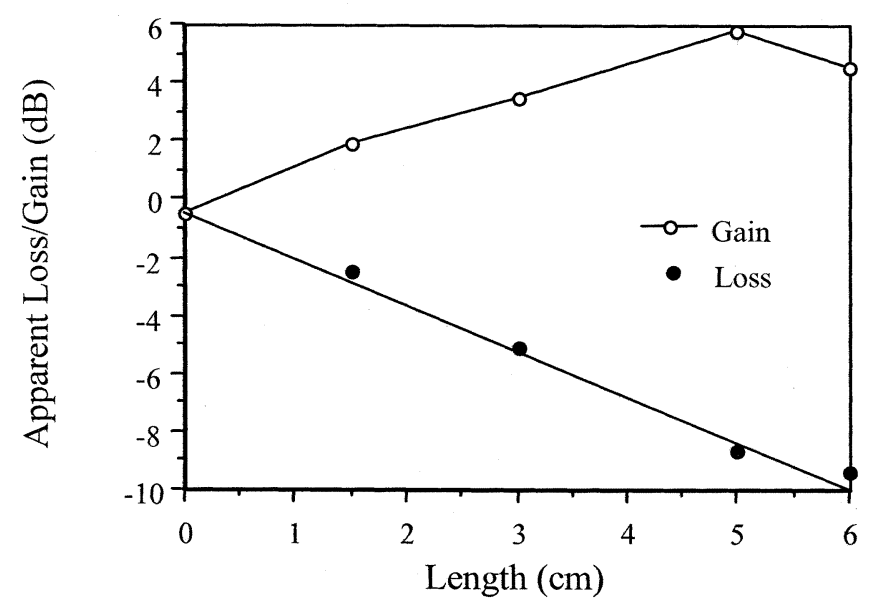

Fig. 11. Variation of gain with length for an $\mathrm{Er} / \mathrm{Yb}$ : AIPSG EDWA with a $1: 1$ Er: $\mathrm{Yb}$ ratio.

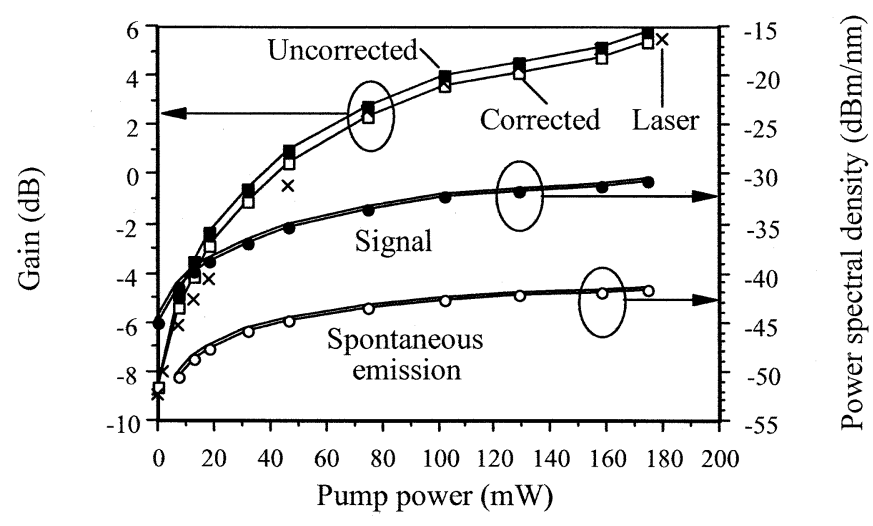

Fig. 12. Variation of signal and ASE power spectral density, gain, and corrected gain with pump power for a 5-cm-long Er/Yb : AlPSG EDWA with a $1: 1 \mathrm{Er}: \mathrm{Yb}$ ratio.

low, explaining the relatively exceptional performance of the device. From the slope of the loss variation, the loss at the erbium peak is $\sim(10.2-0.5) / 6=1.62 \mathrm{~dB} / \mathrm{cm}$, so that the erbium-induced absorption is $\sim 1.62-0.1=1.52 \mathrm{~dB} / \mathrm{cm}$.

The gain variation shows a steady increase with length, until a maximum net gain of $5.75 \mathrm{~dB}$ is obtained at the $5-\mathrm{cm}$ device length described previously; after this, the gain falls. This length corresponds to the optimum for the available pump power. At this length, the background loss is therefore $2 \times$ $0.25 \mathrm{~dB}+5 \times 0.1 \mathrm{~dB}=1.0 \mathrm{~dB}$. The internal gain (i.e., the gain obtained by ignoring the background losses) is therefore $6.75 / 5=1.35 \mathrm{~dB} / \mathrm{cm}$.

Fig. 12 shows the variation of the power spectral density of the signal and the amplified spontaneous emission (ASE) near the signal wavelength with pump power for the same $\mathrm{Er} / \mathrm{Yb}$ : AlPSG EDWA. The data are given as powers in a nominal 1-nm bandwidth. The peak value of the ASE power spectral density is $-41.5 \mathrm{dBm} / \mathrm{nm}$. This figure is similar to a value given in [87], but a correction of $3.5 \mathrm{~dB}$ to cover waveguide-fiber joint loss, WDM coupler loss, fiber connector loss, and OSA power accuracy has been made here. Subtracting the ASE from the signal, a corrected variation of gain with

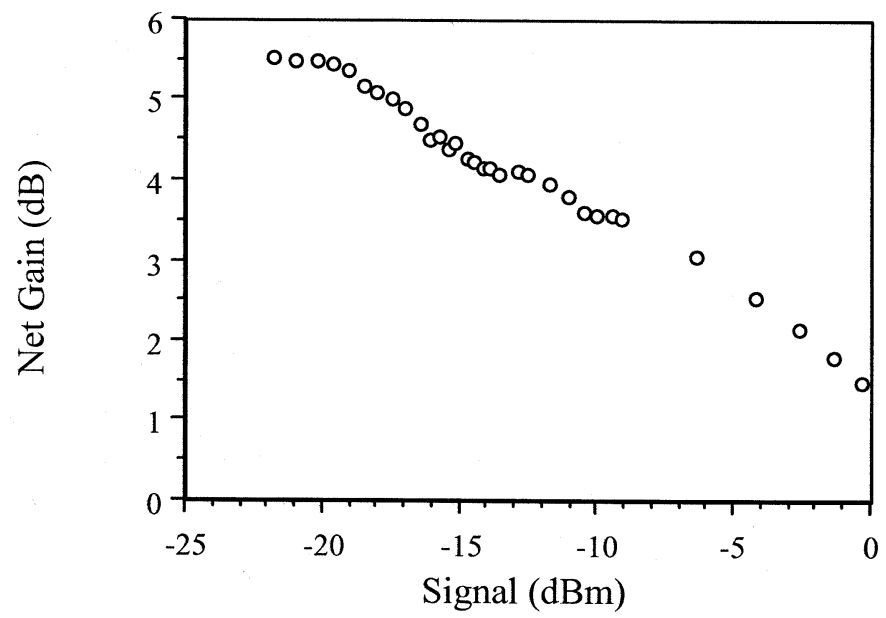

Fig. 13. Variation of gain with signal power obtained using a tuneable laser source at 1535 -nm wavelength.

pump power may be obtained, decreasing the peak gain from 5.75 to $5.5 \mathrm{~dB}$.

Narrow-band measurements of gain were performed using a tuneable laser diode (Agilent 81 642A). The variation of net gain at $1535-\mathrm{nm}$ wavelength with pump power is shown superimposed on Fig. 12 and is in good agreement with the corrected values obtained using the broad-band source. Fig. 13 shows the variation of gain with signal power, showing the onset of gain saturation. The $3-\mathrm{dB}$ point is at approximately $-4 \mathrm{dBm}$.

\section{Estimate of Noise Figure}

The noise figure of an optical amplifier may be estimated from the gain and the spectral density of the ASE power as [1]

$$
\mathrm{NF}=(1 / G)\left\{\left(2 P_{\mathrm{ASE}} / h \nu\right)+1\right\} .
$$

Here, $G$ is the gain, $2 P_{\mathrm{ASE}}$ is the spectral density of the ASE power in both polarizations, $h$ is Planck's constant, and $\nu$ is the frequency. Assuming that $2 P_{\mathrm{ASE}}$ and $G$ have the values at the highest gain measured (so that $2 P_{\mathrm{ASE}}=-41.5 \mathrm{dBm} / \mathrm{nm}$, and $G=5.5 \mathrm{~dB}$, or 3.55), we obtain a noise figure of $1.75 \mathrm{~dB}$. Because the noise figure calculation is relatively sensitive to the absolute value of the ASE power spectral density, and, hence, to an accurate determination of connection losses, this figure is subject to some slight uncertainty.

\section{Lifetime Measurements}

The lifetime of the metastable ${ }^{4} \mathrm{I}_{13 / 2}$ state of $\mathrm{Er}^{3+}$ in the different glass hosts was measured as shown in Fig. 14(a). The EDWAs were pumped using a 980 -nm diode laser as before, but the pump beam was chopped periodically for 5-ms duration at 50-ms intervals using a rotating blade. The decay of the forward-propagating ASE signal was measured using a Ge photodiode coupled to a transimpedance amplifier with a rise time of $\approx 50 \mu \mathrm{s}$.

Fig. 14(b) shows the time variation of the ASE signal for the $\mathrm{Er} / \mathrm{Yb}$ : AlPSG EDWA with a 1:1 Er: Yb ratio, on a log-linear plot. Between $t=0$ and $t=5 \mathrm{~ms}$, there is a rapid rise in the signal to saturation, as the pump is switched on. After $t=5 \mathrm{~ms}$, 


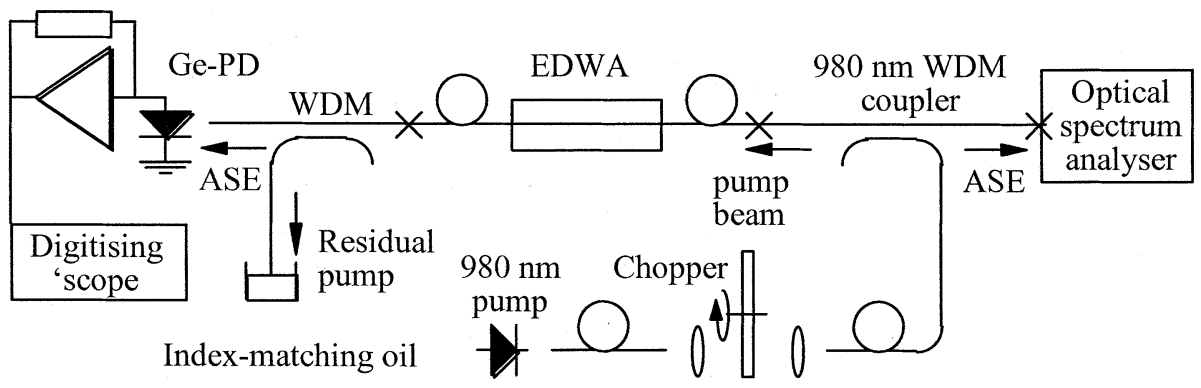

(a)

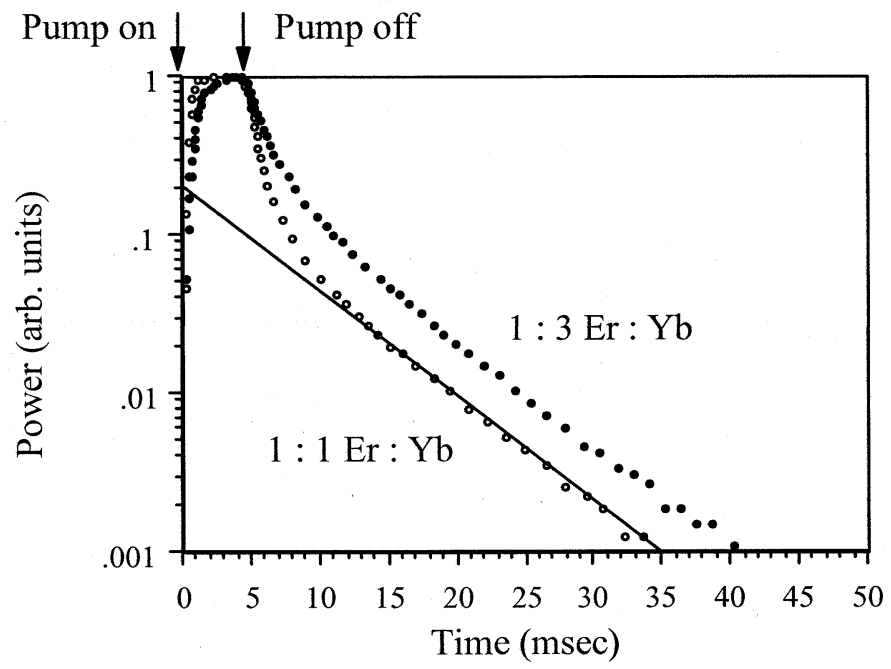

(b)

Fig. 14. (a) Arrangement for measurement of lifetime and (b) time variation of spontaneous emission for 5-cm-long guides in Er/Yb : AlPSG, with 1) $1: 1$ and 2) $1: 3 \mathrm{Er}: \mathrm{Yb}$ ratios.

there is an initial rapid fall as the pump is switched off. The variation becomes linear (i.e., exponentially decaying in time) after $t \approx 10 \mathrm{~ms}$. From the slope in this region, the metastable lifetime can be estimated as $\approx 6.5 \mathrm{~ms}$, comparable to unclustered $\mathrm{Er}^{3+}$ in other silicate hosts.

Fig. 14(b) also shows the result obtained using the $\mathrm{Er} / \mathrm{Yb}$ : AlPSG EDWA with a 1:3 Er: Yb ratio. The metastable lifetime is similar. However, the duration of the initial rapid signal fall is reduced. These results suggest that the ASE signal is derived from two populations with different lifetimes and that reducing the Er concentration to compensate for increased $\mathrm{Yb}$ doping has enhanced the proportion with the longer life.

\section{CONCLUSION}

We have shown how stable, precipitate-free erbium- and ytterbium-doped germanophosphosilicate and aluminophosphosilicate sols may be prepared and used to produce clear glass films on $\mathrm{Si}$ wafers by repetitive spin-coating and rapid thermal annealing. The materials are compatible with previous processes for low-loss passive device fabrication, and this low loss has allowed the construction of operating EDWAs.

Although the maximum rare-earth concentration has been found to be limited in our experiments, a (corrected) net gain of $5.5 \mathrm{~dB}$ has been achieved from a 5-cm-long Er/Yb: AlPSG EDWA containing $0.25 \mathrm{~mol} \% \mathrm{Er}_{2} \mathrm{O}_{3}$ and an $\mathrm{Er}: \mathrm{Yb}$ ratio of $1: 1$. Net gain was also achieved using a similar EDWA with lower Er and higher $\mathrm{Yb}$ concentrations. The results suggest that increased gain will be achievable at lower pump power using the latter composition, albeit in a longer optical path. No net gain was obtained from any other composition lacking $\mathrm{Al}$ or $\mathrm{Yb}$, confirming the importance of these elements in reducing erbium ion quenching and improving the pumping efficiency of an EDWA.

The EDWAs described here have a larger gain per centimeter than devices fabricated by PECVD, suggesting that the sol-gel approach may have advantages in forming the multicomponent glasses needed for amplifiers. Work is continuing to optimize glass composition.

\section{ACKNOWLEDGMENT}

The authors thank Dr. T. V. Clapp and Dr. S. Ojha of Nortel Networks, Harlow, for providing pump lasers and buffered wafers and performing some RIE and PECVD processes, as well as Dr. E. M. Yeatman, Dr. M. M. Ahmad, and Dr. J. Lewandowski for assistance with early work.

\section{REFERENCES}

[1] E. Desurvire, Erbium Doped Fiber Amplifiers. New York: Wiley, 1994.

[2] S. Sudo, Optical Fiber Amplifiers: Materials, Devices and Applications. Norwood, MA: Artech House, 1997.

[3] D. Barbier, "Performances and potential applications of erbium doped planar waveguide amplifiers and lasers," in Proc. OAA'97, Victoria, Canada, July 21-23, 1997. 
[4] P. G. Kik and A. Polman, "Erbium-doped optical waveguide amplifiers on silicon," MRS Bull., pp. 48-54, Apr. 1998.

[5] T. Feuchter, E. K. Mwarania, J. Wang, L. Reekie, and J. S. Wilkinson, "Erbium ion-exchanged waveguide lasers in BK-7 glass," IEEE Photon. Technol. Lett., vol. 4, pp. 542-544, June 1992.

[6] X. H. Zheng and R. J. Mears, "Planar optical waveguides formed by erbium ion exchange in glass," Appl. Phys. Lett., vol. 62, pp. 793-795, 1993.

[7] J. E. Román, P. Camy, M. Hempstead, W. S. Brocklesby, S. Nouh, A. Béguin, C. Lerminaux, and J. S. Wilkinson, "Ion-exchanged Er/Yb waveguide laser at $1.5 \mu \mathrm{m}$ pumped by laser diode," Electron. Lett., vol. 31, pp. 1345-1346, 1995

[8] P. Camy, J. E. Román, F. W. Willems, M. Hempstead, J. C. van der Plaats, C. Prel, A. Béguin, A. M. J. Koonen, J. S. Wilkinson, and C. Lerminiaux, "Ion exchanged planar lossless splitter at $1.5 \mu \mathrm{m}$," Electron. Lett., vol. 32, pp. 321-323, 1996.

[9] S. Honkanen, S. I. Najafi, P. Poyhonen, G. Orcel, W. J. Wang, and J. Chrostowski, "Silver-film ion-exchanged single-mode waveguides in Er-doped phosphate glass," Electron. Lett., vol. 27, pp. 2167-2168, 1991.

[10] T. Ohtsuki, N. Peyghambarian, S. Honkanen, and S. I. Najafi, "Gain characteristics of a high concentration $\mathrm{Er}^{3+}$-doped phosphate-glass waveguide," J. Appl. Phys., vol. 78, pp. 3617-3621, 1995.

[11] P. Fournier, P. Meshkinfam, M. A. Fardad, M. P. Andrews, and S. I. Najafi, "Potassium ion-exchanged Er-Yb doped phosphate glass amplifier," Electron. Lett., vol. 33, pp. 293-295, 1997.

[12] A. Shooshtari, P. Meshkinfam, T. Touam, M. A. Fardad, M. P. Andrews, and S. I. Najafi, "Potassium ion-exchanged $\mathrm{Er} / \mathrm{Yb}$ doped phosphate glass amplifier," Electron. Lett., vol. 34, pp. 704-705, 1998.

[13] D. L. Veasey, D. S. Funk, P. M. Peters, N. A. Sanford, G. E. Obarski, N. Fontaine, M. Young, A. P. Peskin, W. C. Liu, S/ N. Houde Walter, and J. S. Hayden, "Yb/Er codoped and Yb-doped waveguide lasers in phosphate glass," J. Non.-Cryst. Solids, vol. 263, pp. 369-381, 2000.

[14] D. Barbier, J. M. Delavaux, A. Kevorkian, P. Gastaldo, and J. M. Jouanno, "Yb/Er integrated optics amplifiers on phosphate glass in single and double pass configurations," presented at the OFC'95, San Diego, CA, Feb. 26-Mar. 3, 1995, Postdeadline Paper PD3-1.

[15] J.-M. P. Delavaux, S. Granlund, O. Mizuhara, L. D. Tzeng, D. Barbier, M. Rattay, F. Saint André, and A. Kevorjian, "Integrated optics erbium-ytterbium amplifier system in 10-Gb/s fiber transmission experiment," IEEE Photon. Technol. Lett., vol. 9, pp. 247-249, Feb. 1997.

[16] D. Barbier, M. Rattay, F. Saint André, G. Clauss, M. Trouillon, A. Kevorkian, J. M. P. Delavaux, and E. Murphy, "Amplifying four-wavelength combiner, based on erbium/ytterbium-doped waveguide amplifiers and integrated splitters," IEEE Photon. Technol. Lett., vol. 9, pp. 315-317, Mar. 1997.

[17] Y. Jaouen, L. du Mouza, D. Barbier, J. M. Delavaux, and P. Bruno, "Eight-wavelength Er-Yb doped amplifier: Combiner/splitter planar integrated module," IEEE Photon. Technol. Lett., vol. 11, pp. 1105-1107, Sept. 1999.

[18] E. R. Thoen, E. M. Koontz, D. J. Jones, D. Barbier, F. X. Kartner, E. P. Ippen, and L. A. Kolodziejski, "Erbium-ytterbium waveguide laser mode-locked with a semiconductor saturable absorber mirror," IEEE Photon. Technol. Lett., vol. 12, pp. 149-151, Feb. 2000.

[19] A. Polman, A. Lidgard, D. C. Jacobsen, P. C. Becker, R. C. Kistler, G. E. Blonder, and J. M. Poate, "1.54 $\mu \mathrm{m}$ room temperature luminescence of $\mathrm{MeV}$ erbium ion implanted silica glass," Appl. Phys. Lett., vol. 57, pp. 2859-2861, 1990

[20] A. Lidgard, A. Polman, A. Jacobsen, G. E. Blonder, R. Kistler, J. M. Poate, and P. C. Becker, "Fluorescence lifetime studies of MeV erbium implanted silica glass," Electron. Lett., vol. 27, pp. 993-995, 1991.

[21] A. V. Chelnokov, J.-M. Lourtioz, Ph. Boucard, H. Bernas, J. Chaumont, and T. Plowman, "Deep high-dose erbium implantation of low-loss silicon oxynitride waveguides," Electron. Lett., vol. 30, pp. 1850-1852, 1994.

[22] G. N. van der Hoven, R. J. I. M. Koper, A. Polman, C. van Dam, J. W. M. van Uffeien, and M. K. Smit, "Net optical gain at $1.53 \mu \mathrm{m}$ in Er doped $\mathrm{Al}_{2} \mathrm{O}_{3}$ waveguides on silicon," Appl. Phys. Lett., vol. 68, pp. 1886-1888, 1996.

[23] E. Snoeks, G. N. van den Hoven, and A. Polman, "Optimization of an Er-doped silica glass optical waveguide amplifier," IEEE J. Quantum Electron., vol. 32, pp. 1680-1684, Sept. 1996.

[24] M. Nakazawa and Y. Kimura, "Electron-beam vapor-deposited erbiumdoped glass waveguide laser at $1.53 \mu \mathrm{m}$," Electron. Lett., vol. 28, pp. 2054-2056, 1992.

[25] J. Schmulovich, A. Wong, Y. H. Wong, P. C. Becker, A. J. Bruce, and R. Adar, "Er ${ }^{3+}$ glass waveguide amplifier at $1.55 \mu \mathrm{m}$ on silicon," Electron. Lett., vol. 28, pp. 1181-1182, 1992.
[26] J. Schmulovich, Y. H. Wong, G. Nykolyak, P. C. Becker, R. Adar, A. J. Bruce, D. J. Muehlner, G. Adams, and M. Fishsteyn, " 15 dB net gain demonstration in Er glass waveguide amplifier on silicon," presented at the OFC'93, San José, CA, 1993, Postdeadline Paper PD-3.

[27] G. Nykolak, P. C. Becker, J. Schmulovich, Y. H. Wong, D. J. DiGiovanni, and A. J. Bruce, "Concentration-dependent $\mathrm{I}_{(13 / 2)}^{4}$ lifetimes in $\mathrm{Er}^{3+}$-doped fibers and $\mathrm{Er}^{3+}$-doped planar waveguides," IEEE Photon. Technol. Lett., vol. 5, pp. 1014-1016, Sept. 1993.

[28] G. Nykolak, M. Haner, P. C. Becker, J. Schmulovich, and Y. H. Wong, "Systems evaluation of an $\mathrm{Er}^{3+}$-doped planar waveguide amplifier," IEEE Photon. Technol. Lett., vol. 5, pp. 1185-1187, Oct. 1993.

[29] R. N. Ghosh, J. Shmulovich, C. F. Kane, M. R. X. de Barros, G. Nykolak, A. J. Bruce, and P. C. Becker, "8-mW threshold $\mathrm{Er}^{3+}$-doped planar waveguide amplifier," IEEE Photon. Technol. Lett., vol. 8, pp. 518-520, Apr. 1996.

[30] M. P. Hehlen, N. J. Cockroft, T. R. Gosnell, A. J. Bruce, G. Nykolak, and J. Shmulovich, "Uniform upconversion in high-concentration $\mathrm{Er}^{3+}$-doped soda lime silicate and aluminosilicate glasses," Opt. Lett., vol. 22, pp. 772-774, 1997.

[31] Y. C. Yan, A. J. Faber, H. de Waal, P. G. Kik, and A. Polman, "Erbium-doped phosphate glass waveguide on silicon with $4.1 \mathrm{~dB} / \mathrm{cm}$ gain at $1.535 \mu \mathrm{m}$," Appl. Phys. Lett., vol. 71, pp. 2922-2924, 1997.

[32] T. Kitagawa, K. Hattori, M. Shimizu, Y. Ohmori, and M. Kobayashi, "Guided wave laser based on erbium-doped silica planar lightwave circuit," Electron. Lett., vol. 27, pp. 334-335, 1991.

[33] T. Kitagawa, K. Hattori, K. Shuto, M. Yasu, M. Kobayashi, and M. Horiguchi, "Amplification in erbium-doped silica-based planar lightwave circuits," Electron. Lett., vol. 28, pp. 1818-1819, 1992.

[34] K. Hattori, T. Kitagawa, M. Oguma, M. Wada, J. Temmyo, and M. Horiguchi, "Erbium-doped silica-based planar waveguide amplifier pumped by $0.98 \mu$ m laser diodes," Electron. Lett., vol. 29, pp. 357-359, 1993.

[35] M. Oguma, T. Kitagawa, K. Hattori, and M. Horiguchi, "Tunable Er-doped Y-branched waveguide laser," IEEE Photon. Technol. Lett., vol. 6, pp. 586-587, May 1994.

[36] K. Hattori, T. Kitagawa, M. Oguma, Y. Ohmori, and M. Horiguchi, "Erbium-doped silica-based waveguide amplifier integrated with 980/1530 nm WDM coupler," Electron. Lett., vol. 30, pp. 856-857, 1994.

[37] J. A. Bebbington, G. Barbarossa, J. R. Bonar, and J. S. Aitchison, "Rare earth doped silica waveguides on $\mathrm{Si}$ fabricated by flame hydrolysis deposition and aerosol doping," Appl. Phys. Lett., vol. 62, pp. 337-339, 1993.

[38] J. R. Bonar and J. S. Aitchison, "Co-doping effects in rare-earth-doped planar waveguides," Inst. Elect. Eng., Proc. Optoelectronics, vol. 143, pp. 293-297, 1996.

[39] G. D. Maxwell, "Photosensitivity and rare earth doping in flame-hydrolysis-deposited planar silica waveguides," Proc. SPIE, vol. 2695, pp. $16-29,1996$.

[40] K. Shuto, K. Hattori, T. Kitagawa, Y. Ohmori, and M. Horiguchi, "Erbium-doped phosphosilicate glass waveguide amplifier fabricated by PECVD," Electron. Lett., vol. 29, pp. 139-141, 1993.

[41] B. Pedersen, T. Feuchter, M. Polsen, J. E. Pedersen, M. Kristensen, and R. Kromann, "High concentration erbium doped silica-on-silicon grown by plasma enhanced CVD," in Proc ECIO'95, Delft, The Netherlands, Apr. 1995.

[42] S. A. Guldberg-Kjaer, J. Hübner, M. Kristensen, M. R. Poulsen, and M. W. Sckerl, "Planar waveguide laser in Er/Al-doped germanosilicate," Electron. Lett., vol. 35, pp. 302-303, 1999.

[43] M. W. Sckerl, S. A. Guldberg-Kjaer, C. Laurent-Lund, and M. R. Poulsen, "Loss-less planar waveguide 1:4 power splitter at $1550 \mathrm{~nm}$," in Proc. ECOC' 99, Nice, France, 1999, pp. 48-49.

[44] C. E. Chryssou and C. W. Pitt, " $\mathrm{Er}^{3+}$-doped $\mathrm{Al}_{2} \mathrm{O}_{3}$ thin films by plasmaenhanced chemical vapor deposition (PECVD) exhibiting a 55-nm optical bandwidth," IEEE J. Quantum Electron., vol. 34, pp. 282-285, Feb. 1998.

[45] M. Kawachi, "Recent progress in silica-based planar lightwave circuits," Inst. Elect. Eng., Proc. Optoelectronics, vol. 143, pp. 257-262, 1996.

[46] Y. P. Li and C. H. Henry, "Silica-based optical integrated circuits," Inst. Elect. Eng., Proc. Optoelectronics, vol. 143, pp. 263-280, 1996.

[47] P. P. Herrmann and D. Wildmann, "Fabrication of planar dielectric waveguides with high optical damage threshold," IEEE J. Quantum Electron, vol. QE-19, pp. 1735-1738, Dec. 1983.

[48] L. Weisenbach, B. J. J. Zelinski, J. O'Kelly, and J. Morreale, "The influence of processing variables on the optical properties of $\mathrm{SiO}_{2}-\mathrm{TiO}_{2}$ planar waveguides," Proc. SPIE, vol. 1590, pp. 50-57, 1991.

[49] R. L. Roncone, L. A. Weller-Brophy, and B. J. J. Zelinski, "Sol-gel synthesis of planar optical waveguides and integrated components," in $U l$ trastructure Processing of Advanced Materials, R. Uhlmann and D. R. Ulrich, Eds. New York: Wiley, 1992. 
[50] L. Yang, S. Saavedra, N. R. Armstrong, and J. Hayes, "Fabrication and characterization of low-loss, sol-gel planar waveguides," Anal. Chem. vol. 66, pp. 1254-1263, 1994

[51] M. Guglielmi, P. Colombo, L. Mancinelli Degli Espositi, G. C. Righini, and S. Pelli, "Planar and strip optical waveguides by sol-gel method and laser densification," Proc. SPIE, vol. 1513, pp. 44-49, 1990.

[52] D. J. Shaw and T. A. King, "Densification of sol-gel silica glass by laser irradiation," Proc. SPIE, vol. 1328, pp. 474-481, 1990.

[53] F. G. Aráuji, T. Chia, and L. L. Hench, "Laser densification of channel waveguides in gel-silica substrates," J. Sol-Gel Sci. Tech., vol. 2, pp. 729-735, 1994.

[54] B. D. Fabes, B. J. J. Zelinski, G. Lostracco, and D. Taylor, "Laser processing of sol-gel waveguides for integrated optics," presented at the 8th World Ceramics Congr., Florence, Italy, June 28-July 4, 1994, Paper SVII-1 L10.

[55] C.-Y. Li, J. Chisham, M. Andrews, S. I. Najafi, J. D. Mackenzie, and N Peyghambarian, "Sol-gel integrated optical coupler by ultraviolet light imprinting," Electron. Lett., vol. 31, pp. 271-272, 1995.

[56] P. Etienne, P. Coudray, Y. Moreau, and J. Porque, "Photocurable sol-ge coatings: Channel waveguides for use at $1.55 \mu \mathrm{m}$," J. Sol-Gel Sci. Tech., vol. 13 , pp. 523-527, 1998.

[57] M. A. Fardad and M. Fallahi, "Organic-inorganic materials for integrated optoelectronics," Electron. Lett., vol. 34, pp. 1940-1941, 1998.

[58] Y. Sorek and R. Reisfeld, "Sol-gel glass waveguides prepared at low temperature," Appl. Phys. Lett., vol. 63, pp. 3256-3258, 1993.

[59] R. R. A. Syms, A. S. Holmes, W. Huang, V. M. Schneider, and M. Green, "Development of the SC-RTA process for fabrication of sol-gel based silica-on-silicon integrated optic components," J. Sol-Gel Sci. Tech., vol. 13, pp. 509-516, 1998.

[60] A. S. Holmes, R. R. A. Syms, L. Ming, and M. Green, "Fabrication of buried channel waveguides on silicon substrates using spin-on-glass," Appl. Opt., vol. 32, pp. 4916-4921, 1993.

[61] R. R. A. Syms and A. S. Holmes, "Reflow and burial of channel waveguides formed in sol-gel glass on Si substrates," IEEE Photon. Technol. Lett., vol. 5, pp. 1077-1079, Sept. 1993.

[62] E. M. Yeatman, K. Pita, M. M. Ahmad, A. Vannucci, and A. Fiorello, "Strip-loaded high-confinement waveguides for photonic applications," J. Sol-Gel Sci. Tech., vol. 13, pp. 517-521, 1998.

[63] R. M. Almeida and E. E. Christensen, "Crystallization behavior of $\mathrm{SiO}_{2}-\mathrm{TiO}_{2}$ sol-gel thin films," J. Sol-Gel Sci. Tech., vol. 8, pp. $409-413,1997$

[64] A. S. Holmes and R. R. A. Syms, "Fabrication of low-loss channe waveguides in sol-gel glass on silicon substrates," presented at the 8th World Ceramics Congr., Florence, Italy, June 28-July 4, 1994, Paper SVII-1 LO9.

[65] R. R. A. Syms, V. Schneider, W. Huang, and A. S. Holmes, "Low loss achieved in sol-gel based silica-on-silicon integrated optics using borophosphosilicate glass," Electron. Lett., vol. 31, pp. 1833-1834, 1995.

[66] R. R. A. Syms, W. Huang, and V. M. Schneider, "Optimization of borophosphosilicate glass compositions for silica-on-silicon integrated optical circuits fabricated by the sol-gel process," Electron. Lett., vol. 32, pp. 1233-1234, 1996

[67] R. R. A. Syms, V. M. Schneider, W. Huang, and M. M. Ahmad, "High- $\Delta n$ silica-on-silicon channel waveguides based on sol-gel germanophosphosilicate glass," Electron. Lett., vol. 33, pp. 1216-1217, 1997.

[68] W. V. Moreshead, J.-L. R. Nogués, and R. H. Krabill, "Preparation, processing and fluorescence properties of neodymium-doped silica glass prepared by the sol-gel process," J. Non-Cryst. Solids, vol. 121, pp. 267-272, 1990

[69] I. M. Thomas, S. A. Payne, and G. D. Wilke, "Optical properties an laser demonstration of Nd-doped sol-gel silica glasses," J. Non-Cryst. Solids, vol. 151, pp. 183-194, 1992

[70] D. Moutonnet, R. Chaplain, M. Gauneau, Y. Pelous, and J. L. Rehspringer, "Realization and characterization of $\mathrm{Er}$ and $\mathrm{Yb}$ glasses obtained by the sol-gel method," Mater. Sci. Eng., vol. B9, pp. 455-457, 1991.

[71] G. C. Righini, M. A. Forastiere, M. Guglielmi, and A. Martucci, "Rareearth doped sol-gel waveguides: A review," Proc. SPIE, vol. 3280, pp. $57-66,1998$.

[72] X. Orignac and R. M. Almeida, "Silica-based sol-gel optical waveguides on silicon," Inst. Elect. Eng., Proc. Optoelectronics, vol. 143, pp. 287-292, 1996

[73] D. Barbier, S. Orignac, X. M. Du, and R. M. Almeida, "Improved composition for sol-gel rare earth doped planar waveguides," J. Sol-Gel Sci. Tech., vol. 8, pp. 1013-1016, 1997.

[74] B. T. Stone and K. L. Bray, "Fluorescence properties of $\mathrm{Er}^{3+}$-doped sol-gel glasses," J. Non-Cryst. Solids, vol. 197, pp. 136-144, 1996.
[75] A. Bahtat, M. Bouazaoui, M. Bahtat, and J. Mugnier, "Fluorescence of $\mathrm{Er}^{3+}$ ions in $\mathrm{TiO}_{2}$ planar waveguides prepared by a sol-gel process," Opt. Commun., vol. 111, pp. 55-60, 1994.

[76] S. Orignac, D. Barbier, X. M. Du, and R. M. Almeida, "Fabrication and characterization of sol-gel planar waveguides doped with rare earth ions," Appl. Phys. Lett., vol. 69, pp. 895-897, 1996.

[77] E. M. Yeatman, M. M. Ahmad, O. McCarthy, A. Vannucci, P. Gastaldo, D. Barbier, D. Mongardien, and C. Moronvalle, "Optical gain in Er-doped $\mathrm{SiO}_{2}-\mathrm{TiO}_{2}$ waveguides fabricated by the sol-gel technique," Opt. Commun., vol. 164, pp. 19-25, 1999.

[78] C. Coutier, W. Meffre, P. Jenouvrier, J. Fick, M. Audier, R. Rimet, B. Jacquier, and M. Langlet, "The effects of phosphorus on the crystallization and photoluminescence behavior of aerosol-gel deposited $\mathrm{SiO}_{2}-\mathrm{TiO}_{2}-\mathrm{Er}_{2} \mathrm{O}_{2}-\mathrm{P}_{2} \mathrm{O}_{2}$ thin films," Thin Solid Films, vol. 392, pp. $40-49,2001$

[79] M. Benatsou, B. Capoen, M. Bouazaoui, W. Tchana, and J. P. Vilcot, "Preparation and characterization of sol-gel derived $\mathrm{Er}^{3+}: \mathrm{Al}_{2} \mathrm{O}_{3}-\mathrm{SiO}_{2}$ planar waveguides," Appl. Phys. Lett., vol. 71, pp. 428-430, 1997.

[80] M. Benatsou, B. Capoen, and M. Bouazaoui, "Structure and optical properties of sol-gel derived aluminosilicate planar waveguides doped with $\mathrm{Er}^{3+}$ ions," J. Sol-Gel Sci. Tech., vol. 13, pp. 529-533, 1998.

[81] A. S. Holmes, R. R. A. Syms, K. Ueki, and H. Yanagawa, "Er-doped silica waveguide using sol-gel method," presented at the 55th Autumn Meeting, Japan Soc. Applied Physics, Nagoya, Sept. 19-22, 1994, Paper 21-P-R-5.

[82] X. Orignac, D. Barbier, X. M. Du, R. M. Almeida, O. McCarthy, and E. Yeatman, "Sol-gel silica/titania-on-silicon Er/Yb-doped waveguides for optical amplification at $1.5 \mu \mathrm{m}$," Opt. Mater, vol. 12, pp. 1-18, 1999.

[83] M. Benatsou and M. Bouazaoui, "Fluorescence properties of sol-gel derived $\mathrm{Er}^{3+}: \mathrm{SiO}_{2}-\mathrm{GeO}_{2}$ planar waveguides," Opt. Commun., vol. 137 , pp. $143-150,1997$.

[84] C. Strohhofer, S. Capecci, J. Fick, A. Martucci, G. Brusatin, and M. Guglielmi, "Active optical properties of erbium doped $\mathrm{GeO}_{2}$ based sol-gel planar waveguides," Thin Solid Films, vol. 326, pp. 99-105, 1998.

[85] S. Y. Chen, C. C. Ting, and C. H. Li, "Fluorescence enhancement and structural development of sol-gel derived $\mathrm{Er}^{3+}{ }_{\text {-doped }} \mathrm{SiO}_{2}$ by yttrium codoping," J. Mater. Chem., vol. 12, pp. 1118-1123, 2002.

[86] L. H. Slooff, M. J. A. de Dood, A. van Blaaderen, and A. Polman, "Effects of heat treatment and concentration on the luminescence properties of erbium-doped silica sol-gel films," J. Non-Cryst. Solids, vol. 296, pp. 158-164, 2001

[87] W. Huang, R. R. A. Syms, E. M. Yeatman, M. M. Ahmad, T. V. Clapp, and S. M. Ojha, "Fiber-device-fiber gain from a sol-gel erbium doped waveguide amplifier," IEEE Photon. Technol. Lett., vol. 14, pp. 959-961, July 2002.

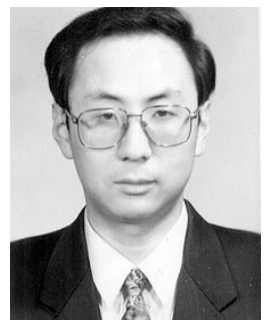

W. Huang was born in Yantai City, China. He received the B.Eng. and M.Sc. degrees from Tsinghua University, Beijing, China, in 1984 and 1986, respectively and the Ph.D. degree from Imperial College of Science, Technology, and Medicine, London, U.K., in 1999.

From 1986 to 1994 , he worked as a Lecturer in the Department of Electronic Engineering, Tsinghua University. From 1999 to 2001, he worked at the Department of Electronics and Electrical Engineering, Glasgow University, U.K., before returning to Imperial, where he is currently a Research Associate. His research interest is in the field of integrated optics and micromachining.

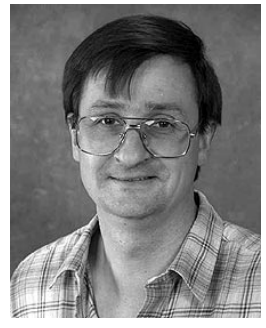

R. R. A. Syms (M'98-SM'02) was born in Norfolk, VA, in 1958. He received the B.A. degree in engineering science and the D.Phil. degree in volume holographic optical elements from Worcester College, Oxford, U.K., in 1979 and 1982, respectively.

He has been Head of the Optical and Semiconductor Devices Section in the Department of Electrical and Electronic Engineering, Imperial College, London, U.K., since 1992 and Professor of Microsystems Technology since 1996 . He has published approximately 90 papers and two books on holography, optical devices, integrated optics, and microengineering. His current interests are in silica-on-silicon integrated optics and silicon-based optical MEMS 